\title{
Entre o especialismo e o apoio: psicólogos no Núcleo de Apoio à Saúde da Família
}

\author{
Diogo de Sousa* \\ Isabel Fernandes de Oliveira \\ Ana Ludmila F. Costa \\ Universidade Federal do Rio Grande do Norte, Programa de Pós-graduação em Psicologia. Natal, RN, Brasil
}

\begin{abstract}
Resumo: A inserção do psicólogo em equipes multiprofissionais e interdisciplinares para suporte às equipes de saúde da família, a partir da criação dos Núcleos de Apoio à Saúde da Família em 2008, foi priorizada, ainda que sem um claro perfil para sua atuação. Isso levou ao questionamento das implicações de um trabalho voltado à atenção e gestão para a Psicologia. Objetivou-se analisar o processo de implantação do NASF e a prática dos psicólogos em dois municípios do estado do Rio Grande do Norte. Utilizou-se análise de documentos oficiais e roteiros de entrevistas semiestruturadas distintos, para psicólogos (um do município A e dois do município B) e coordenadores (dois, um de cada município). Pôde-se inferir que a atuação psicológica revela enfoques tradicionais e uma reprodução de atividades de outras instituições. Conclui-se que as diferenças nos processos de implantação dos serviços criam os próprios instrumentos para reversão dessa lógica.
\end{abstract}

Palavras-chave: Núcleos de Apoio à Saúde da Família, atuação do psicólogo, políticas de saúde, saúde da família.

Na transição dos séculos, o Brasil tem sido regido por ordens neoliberais puras ou híbridas, cujas repercussões não estão completamente dimensionadas. A manutenção de uma poupança externa para fins de "desenvolvimento" (Mattos, 2001) e os compromissos de austeridade acordados (Netto, 2001) não foram fatos isolados. Sedimentou-se, na realidade, um financiamento para o subdesenvolvimento (Bresser-Pereira, 2002).

O histórico enxugamento do ônus estatal com a saúde pública alargou o abismo com o setor privado a ponto de constitucionalizar o Sistema Único de Saúde (SUS), um sistema híbrido e contraditório (Menicucci, 2006). Sua fundação e o posterior intento de reorganização estratégica remontam a derivações contrárias: apesar de baseado em perspectivas universais e democráticas de saúde (a exemplo do que ocorre em Cuba, Canadá e Inglaterra), a reorganização do SUS com as Estratégias de Saúde da Família (ESF) levou à focalização e racionalização do modelo americano da atenção primária em saúde.

O Projeto de Expansão e Consolidação da Saúde da Família (PROESF) foi pactuado e negociado com o Banco Internacional para a Reconstrução e o Desenvolvimento (BIRD) com financiamento de 275 bilhões de dólares e vigência de sete anos, a partir de 2003 (Heimann \& Mendonça, 2005). Tal projeto consolidava a ESF como modelo central da atenção básica, e substituía os tradicionais serviços ambulatoriais pelas Unidades de Saúde da Família (USF), apesar desse aspecto "estratégico" já figurar nos bastidores desde a elaboração do Programa de Saúde da Família (PSF), em 1994 (Viana \& Dal Poz, 2005). Como "porta de entrada" de uma rede hierarquizada, a atenção

* Autor correspondente: dr_desousa@yahoo.com.br básica se configura por ações de promoção, proteção, prevenção, diagnóstico, tratamento, reabilitação e manutenção da saúde (Ministério da Saúde, 2006).

Tal expansão, contudo, ocorreu apenas em abrangência, sem muitas mudanças positivas na prática. Há quase 20 anos esse processo enfrenta desafios, como a crescente procura por serviços de média e alta complexidade e a "distinção" de financiamento entre os diversos níveis da rede, o que gera superlotação e impasses no sistema de referência e contra referência da assistência. Ademais, embora haja significativo avanço teórico em saúde, pouco se operacionaliza. A alta complexidade como "a única que resolve os agravos", a dificuldade de ações preventivas distintas de campanhas preventivas, políticas públicas que garantam as chamadas "condições mínimas de existência" (Cohn, 2005) são questões não superadas; desafios de estreita ligação com as contradições do "jogo político" por trás do SUS.

Fez-se praxe que o Ministério da Saúde institua novos serviços quando seus predecessores não alcançam os objetivos almejados. Porém, com o Núcleo de Apoio à Saúde da Família (NASF) criado em 2008 pela portaria ${ }^{\circ} 154 / \mathrm{GM}$ foi um pouco diferente (Ministério da Saúde, 2008a). O momento propício se deu quando as ESF não achavam o caminho necessário para esse suporte "especializado" nos hospitais (sobretudo devido à lotação) e centros de referência (em função da pouca capacidade). O NASF, no entanto, não é programa, centro ou nova "porta de entrada" para o SUS. É um serviço de suporte, portanto não repete funções de outras instituições, nem ocupa o lugar destinado à ESF na atenção básica.

Poucos são os estudos sistemáticos sobre o NASF, haja vista sua realidade recente e o ineditismo de suas 
práticas no contexto da atenção básica. Somente a partir de 2008 passou a ser contemplado de forma mais expressiva entre os periódicos de Fisioterapia, Educação Física e Terapia Ocupacional.

Ao se atentar para a crítica das diretrizes e políticas, assim como para as nuanças do trabalho em saúde, o presente estudo buscou compreender o processo de implantação do NASF e a dinâmica de atuação dos psicólogos aí inseridos. Compreende-se que tal processo repercute física, institucional e politicamente diretamente sobre o perfil profissional almejado pelos gestores e sobre a prática efetiva. Assim, tornou-se pertinente uma investigação, não como mapeamento em todo o estado, mas focalizada em municípios chave. Dado o recente percurso do NASF e do psicólogo nesse contexto, faz-se necessário um breve detalhamento do serviço e um levantamento das principais questões acerca da atuação da Psicologia no setor.

\section{O núcleo de apoio à saúde da família}

O NASF tem como embrião institucional o Núcleo de Atenção Integral à Saúde da Família (NAISF), apresentado através da portaria 1065/GM de 4 de julho de 2005, revogada no dia seguinte. Sua divulgação mobilizou alguns municípios a desenvolverem projetos similares: em Sobral, município do Ceará, foram realizadas experiências com profissionais não previstos na Residência Multiprofissional em Saúde da Família (RMSF) (Sales \& Pagani, 2004); e em Campinas, São Paulo, foi instituído o programa Paidéia Saúde da Família, baseado no método Paidéia (Campos, 2006). Do último, advêm conceitos chave para o NASF: o apoio matricial e a equipe de referência (Campos, 1999, 2006).

As equipes de referência são o elo mais próximo à população atendida em determinado nicho funcional da ESF. Não vinculadas a uma clientela exclusiva, coordenam o cuidado a grupos organizados em função "do objetivo de cada unidade de saúde, as características de cada local e a disponibilidade de recursos" (Campos, 1999, p. 4). As equipes de apoio se inserem nesse arranjo e quebram a verticalidade da equipe de referência, conectando-a horizontalmente com outras equipes através do matriciamento. $\mathrm{O}$ apoio matricial consiste em uma ferramenta que potencializa a corresponsabilização e dilui o poder de decisão dos membros, contrapondo-se à hierarquia burocrática e à imposição de saberes dominantes.

Com a portaria $n^{0} 154 / \mathrm{GM}$ de 24 de janeiro de 2008 (Ministério da Saúde, 2008a) instituiu-se o NASF, assim como sua estruturação, modalidades, áreas estratégicas e quadro de profissionais. Os NASFs se organizam em duas modalidades: para a maioria dos municípios, se instalaram o NASF 1, com 1 equipe NASF (ENASF) a cada 8 ESFs com exceção da Região Norte, onde em municípios com menos de $100.000 \mathrm{hab} / \mathrm{km}^{2}$ a razão passa para $1 / 5$; nos municípios com menos de $10 \mathrm{hab} / \mathrm{km}^{2}$ se instalam os NASFs 2, com apenas 1 ENASF.

As equipes também se distinguem em função do tipo de NASF. A ENASF 1 tem um mínimo de 5 profissionais de nível superior com ocupações não coincidentes, que podem ser psicólogo, assistente social, educador físico, farmacêutico, fisioterapeuta, fonoaudiólogo, nutricionista, pediatra, terapeuta ocupacional, acupunturista, ginecologista, homeopata e psiquiatra. A ENASF 2 exclui os quatro últimos e prevê o mínimo de 3 profissionais. Anexadas à portaria $\mathrm{n}^{0} 154 / \mathrm{GM}$, as ações foram apenas sumarizadas. Apenas em 2009, o documento Diretrizes do NASF (Ministério da Saúde, 2009a) pormenorizou áreas estratégicas, ações, processos de trabalho, responsabilidades e princípios teóricos fundamentados e referenciados.

Multiprofissionalismo e interdisciplinaridade são a tônica do documento, sem prever funções específicas e integrando toda a equipe às nove áreas estratégicas priorizadas: saúde mental, saúde da criança, saúde do adolescente e do jovem, reabilitação/saúde integral da pessoa idosa, saúde da mulher, serviço social, atividades físicas/práticas corporais, assistência farmacêutica e práticas integrativas e complementares. As diretrizes para o trabalho da equipe são: ação interdisciplinar e intersetorial, educação permanente em saúde dos profissionais, implementação da noção de território, integralidade das ações, participação social, educação popular, promoção da saúde e humanização (Ministério da Saúde, 2009a).

São três os tipos de processos de trabalho a serem desenvolvidos pelas ENASF: o atendimento compartilhado com a ESF; intervenções específicas com usuários e/ou famílias, previamente acordadas com as ESFs responsáveis; e as ações comuns às equipes, as quais, por sua vez, são: identificar as atividades a serem adotadas e o público prioritário de cada uma; integrar e planejar as atividades desenvolvidas pelas ESF; desenvolver práticas intersetoriais (educação, esporte, cultura etc.); e fomentar a gestão integrada com usuários pelos Conselhos de Saúde, avaliando o desenvolvimento, implementação e impacto das ações por indicadores previamente pactuados (Ministério da Saúde, 2009a). Outra função da ENASF é a elaboração de material de divulgação e educativo sobre o serviço.

$\mathrm{O}$ apoio preconizado no NASF se dá em duas vertentes: o apoio à atenção (que inclui o apoio matricial, a clínica ampliada e o Projeto Terapêutico Singular - PTS), e o apoio à gestão (referente à pactuação do apoio e o Projeto de Saúde no Território - PST).

A clínica ampliada compreende uma perspectiva de trabalho baseada na concepção do processo saúde-doença para além da medicalização e do biologicismo, incluindo determinantes sociais e construções subjetivas (Cunha, 2005), formando o modelo biopsicossocial de saúde (Ministério da Saúde, 2009b). Se o deslocamento do apoio das equipes de matriciamento em saúde mental (Ministério da Saúde, 2003) para as ENASFs implica uma reestruturação organizativa da Atenção Básica, a clínica ampliada traz implicações sobre a construção do Projeto Terapêutico Singular (PTS) - este funciona como uma "ampliação" para a equipe e usuários da discussão de casos, definindo hipóteses diagnósticas, metas, responsabilidades e sempre reavaliando com flexibilidade. 
$\mathrm{O}$ apoio à gestão se dá no próprio processo de implantação e implementação do NASF. A pactuação do apoio se divide em dois momentos: a avaliação conjunta da situação inicial do território, entre gestores, ESF e população, discutindo as condições e necessidades do município, as temáticas a incentivar e a formação da ENASF (Ministério da Saúde, 2009a); e a própria pactuação formal de ações e metas com a ENASF, considerando objetivos, prioridades, critérios de condução de casos, avaliação das equipes e resolução de conflitos (Ministério da Saúde, 2009a). O Projeto de Saúde no Território (PST) operacionaliza os pactos estabelecidos, inserindo outras instituições (públicas e privadas) do território e atores envolvidos em um projeto de diferentes planos de cuidado. Se divide em três etapas: a preparação do projeto, identificando e justificando a priorização da área/população vulnerável/em risco, definindo objetivos e ações da ESF e identificando os atores e instituições relevantes num espaço coletivo de discussão entre ESF e ENASF; o planejamento e implementação, incorporando os atores responsabilizados (usuários, comunidade, setores públicos e privados etc.) em uma gestão participativa, estabelecendo sinergias, consensos, pactuações, corresponsabilizações e, se necessário, reformulações; e a avaliação, problematizando os resultados, os entraves e os objetivos cumpridos.

Tal papel horizontal da gestão é de suma importância para o pleno funcionamento do serviço, com implicações diretas nas ações. Assim, a implantação de um serviço é tida como processo, desenvolvimento, sem formatação hermética ou consolidação de uma "atuação final" que suplante situações do cotidiano. No entanto, há entraves estruturais para essa horizontalidade, tais como as orientações verticais do Ministério da Saúde e seu calendário "campanhista", as burocracias das áreas racionalizadoras da saúde, presentes ainda no setor administrativo e de gestão, e a incipiente formação de profissionais inseridos no mercado pelo setor saúde?

Uma particularidade da portaria ministerial $\mathrm{n}^{0} 154$ tem relação explícita com trabalhadores de saúde mental, especificamente o psicólogo. É recomendado oficialmente que as ENASFs apresentem pelo menos um profissional de saúde mental (psicólogo ou psiquiatra) nas equipes mínimas, "tendo em vista a magnitude epidemiológica dos transtornos mentais" (Ministério da Saúde, 2008a, p.2). Por sua vez, na portaria $\mathrm{n}^{\circ} 409$ publicada no mesmo ano (Ministério da Saúde, 2008b), é esperado que o psicólogo ingresso nos NASFs, para fins de legitimação das equipes e provimento de custeio, pertença a uma entre duas classificações reguladas pela Classificação Brasileira de Ocupações (CBO): psicólogo clínico ou psicólogo social. Ainda que não haja definições consensuais sobre tais modelos de profissional de Psicologia, não se pode deixar de mencionar a radical diferença entre o psicólogo clínico e

1 Apesar de ser uma questão imprescindível e, portanto, central para muitos estudos, as implicações da formação acadêmica e suas derivações para atuação no NASF não constituíram foco deste estudo. o social, seja em termos de público atendido, abordagem teórica, contextos de atuação, entre outros aspectos.

Tal indefinição de perfil traz à tona questionamentos e discussões sobre a atuação do profissional de Psicologia voltada para a saúde pública e seu papel ao lidar com as questões sociais que cercam as políticas e instituições governamentais envolvidas, discussão essa que percorre algumas décadas.

\section{Método}

O estudo tem natureza exploratória, dado o ineditismo de estudos sobre o NASF no estado do Rio Grande do Norte, e caráter comparativo, considerando dois contextos distintos de implantação e práticas psicológicas. A pesquisa se realizou em dois NASFs, um em cada município eleito por critérios de representatividade no cenário estadual: um pelo histórico pioneiro na implantação de um NASF no estado (município A), e outro por ter uma reconhecida rede de saúde mental estruturada em comparação aos demais do estado (município B). Entre 2010 e 2011, foram realizadas entrevistas com os profissionais de Psicologia dos serviços em questão (um no município A e dois do município B) e com os coordenadores (um de cada município), guiadas por roteiros semiestruturados distintos para cada categoria. Complementarmente, também se realizou aprofundada análise dos documentos oficiais que regulam os mesmos.

Os roteiros das entrevistas contêm 37 tópicos-guia para os psicólogos (Roteiro A) e 17 para os coordenadores (Roteiro B), organizados em blocos temáticos. O Roteiro A se divide em 4 blocos: 1) dados sociodemográficos, 2) formação acadêmica, 3) implantação do NASF e 4) atuação do psicólogo. O $3^{\circ}$ bloco tem caráter facultativo, dada a rotatividade dos profissionais do NASF, que podem não ter participado do processo de implantação. $\mathrm{O}$ último bloco tem por objetivo detalhar as atividades dos psicólogos no serviço no que se refere ao contexto em que atuam, às dificuldades, às relações entre as equipes e aos referenciais teóricos que sustentam a prática desses profissionais.

O Roteiro B, que norteia o aporte aos coordenadores do NASF, apresenta 2 blocos: dados sociodemográficos e processo de implantação do NASF. Esse segundo bloco parte de uma pergunta deflagradora sobre como ocorreu o processo de implantação do NASF sob sua responsabilidade e a articulação de sua participação nesse processo. Os roteiros foram construídos a partir de um processo de experimentação piloto com um profissional de Psicologia de outro NASF do estado.

O viés de análise é empático a um olhar materialista, histórico e dialético, compartilhando de preocupações da tradição marxista sobre a pesquisa e construção de corpo teórico acerca de um dado objeto de estudo 2 .

2 Segundo Netto (2011), os estudos marxistas consistem, em linhas gerais, na reprodução no campo do pensamento, do ideal, de um movimento real do objeto. 


\section{Resultados e discussão}

Em ambas as instituições estudadas, apesar de haver processos de implantação peculiarmente distintos, desenvolveram-se culturas intrinsecamente irmãs. A priorização de um atendimento exclusivamente ambulatorial aparece em ambos os municípios, não só como orientação direta da gestão municipal ou da coordenação dos serviços, mas também como apelo das próprias Equipes de Saúde da Família.

No município A, desenvolveu-se o que se nomeou de "ambulatório não-institucionalizado", na medida em que no lugar do NASF passou a funcionar um ambulatório de especialidades sem estar vínculo oficial a alguma instituição. Já no município B, se deu o "ambulatório comunitário", atuando de forma itinerante em cada Unidade de Saúde da Família, visto que não se dispunha de sede física, como no município A.

Os processos de implantação ilustram como ocorreu o direcionamento dessas práticas. No município A, houve o que se pode classificar como um processo de implantação "atravessado". Houve duas equipes NASFs em momentos distintos: a primeira acompanhou as oficinas de treinamento e discussão de documentos oficiais, portarias e o projeto NASF do município. Trabalhou durante três meses e foi dissolvida junto com as equipes de outras instituições, devido a uma mudança de governo no município. A nova gestão municipal contratou um grande quadro profissional para repor os que foram exonerados, mas sem oficializar onde seria a lotação de cada contratado. Durante aproximadamente um semestre de trabalho, tais profissionais desempenharam atividades ambulatoriais com o objetivo de melhorar os indicadores de saúde do município. Após isso, a equipe NASF foi nomeada repentinamente, sem haver qualquer processo de "reimplantação", tendo que organizar sua prática sem o apoio da gestão.

No município B, pode se considerar que houve uma implantação "modelo". Os gestores, as Equipes de Saúde da Família e a própria equipe NASF pactuaram durante fóruns, antes da própria implantação, as ações que deveriam ser desenvolvidas. As duas ENASFs do município passaram por oficinas de treinamento conjunto, elaboraram um questionário para avaliar as principais demandas das ESFs e tiveram um grande entrosamento interprofissional desde cedo. No entanto, como mencionado anteriormente, tal "planejamento de excelência" não esteve à altura da demanda, principalmente das ESFs, para que houvesse atendimento especializado como referência, que duraria dois meses consecutivos. A diferença que se revela entre os dois municípios estudados vai além do tempo de duração desses "ambulatórios".

Um grande empecilho para atuação do NASF, até mesmo percebido pelas próprias equipes e coordenações, é a consequente criação de uma demanda não atendida. Com o funcionamento exclusivo do atendimento ambulatorial, o crescimento da demanda, principalmente para os profissionais de Psicologia do serviço, pareceu ser subdimensionado.
A mudança para uma dinâmica de atuação mais próxima aos ditames oficiais, que no município A ocorreu mais por pressão da gestão do que por uma reflexão da equipe como no município $B$, esbarrou em uma gigantesca demanda que não encontrava lugar nos moldes das ações previstas para o NASF e que havia se acostumado aos atendimentos por especialidades.

A preocupação e apoio da gestão e coordenação do serviço no município B, assim como a decisão da ENASF, conseguiu estabelecer uma nova forma de funcionamento com o incremento das atividades coletivas, criação de grupos, atividades lúdicas e projetos intersetoriais. Por meio de um trabalho de ressignificação do papel do NASF frente à rede, contando com total apoio da coordenação do serviço, ambas ENASFs remodelaram a relação com as ESFs do município $\mathrm{B}$, pactuando ações mais promotoras de saúde que assistencialistas. Apesar disso, a manutenção do atendimento ambulatorial se fez necessária para esses NASFs devido à grande demanda criada, que ocorre separadamente das práticas coletivas, configurando uma prática dual. Um indicativo de que a estratégia tem obtido retorno é que a porcentagem da carga horária destinada aos atendimentos foi reduzida da exclusividade para aproximadamente $25 \%$ do total (uma semana para atendimentos, ficando três para atividades coletivas).

No município A, a situação é ainda mais delicada dada a sua deficiência no quesito "implantação". Para uma carga horária de 40 horas semanais, o NASF do município A divide seu cronograma em: 24 horas para o atendimento $(60 \%), 10$ horas para visitas domiciliares $(25 \%)$ e apenas 6 horas (15\%) para as atividades coletivas, nomeadas pela coordenação do referido NASF como "o dia do NASF". Tal organização em muito se deve à forma como a relação ESF-ENASF se opera no município A. A forma como a segunda equipe NASF do município foi apresentada tanto à população quanto à rede de saúde, não tendo processo de implantação propriamente dito ou pactuação de ações com outras instituições, deixou uma marca difícil de desfazer.

O "dia do NASF" também é um bom exemplo de como a dinâmica que se estabeleceu no início da atuação da equipe NASF repercutiu sobre as expectativas da ESF e também da população. Tal atividade se configurava ciclicamente, havendo a mesma atividade em cada USF durante as manhãs de sexta-feira até se contemplarem todas as unidades do município. $\mathrm{O}$ que de fato acontecia não eram as visitas preconizadas, mas sim atendimentos individualizados, ficando cada profissional do NASF em uma sala separada - atendimentos que aconteciam tanto por pressão da ESF como da população. Tem-se, então, que a suposta atividade coletiva do NASF A resumia-se a um atendimento in loco, realizado no espaço das USF.

As atividades coletivas do NASF do município B, apesar de organizadas em cronograma, ainda revelam algumas dificuldades da equipe e coordenação. É relatado pela própria coordenação que, apesar de desenvolverem atividades além do atendimento individual, o próprio NASF assume que não realiza o apoio matricial ou as demais 
ações preconizadas no caderno de diretrizes (Ministério da Saúde, 2009a). Apesar disso, a equipe reitera seu entrosamento, por vezes citando o aspecto interdisciplinar previsto nos ditames oficiais. $\mathrm{O}$ que se percebe nas ações, na prática, não é o "nível da transdisciplinaridade" - existe, de fato, um grande entrosamento entre as duas ENASFs e entre seus membros, uma grande troca de informações e discussão de casos, mas em relação às atividades coletivas ainda repercute uma atuação fragmentada.

Há separação das áreas específicas de cada profissional por seus conhecimentos específicos de atuação, perfazendo uma orientação mais "disciplinar" no trato à população. No entanto, há também momentos onde apenas se auxilia com habilidades pessoais, possibilitando que os membros da equipe trabalhem "juntos".

Há um não reconhecimento por parte das psicólogas entrevistadas das implicações que as ações coletivas possam ter para a atuação conjunta dos profissionais. Isso não parece se dar por um direcionamento das ações para alguma especificidade de algum profissional em particular, e tampouco pode ser atribuído às diferentes e conflitantes visões do contexto social em que se inserem tais práticas, advindas de formações muitas vezes díspares tanto entre si quanto da concepção de sujeito biopsicossocial preconizada pelas políticas de atenção básica em saúde.

Por outro lado, o "não se implicar" parece estar estreitamente ligado a uma perspectiva disciplinar que atravessa a prática das ENASFs. A preocupação de definir claramente para as ESFs - principalmente agentes comunitários no curso de capacitação ocorrido no processo de ressignificação do NASF - as atribuições "específicas" de cada profissional da ENASF não só estão relacionadas com preocupações oriundas do atendimento individual e seu aspecto "descolado" das demais práticas, mas relacionam-se também a uma reprodução da lógica compartimentalizada de atendimento ambulatorial em saúde, resultando em dificuldades de implementação de práticas coerentes com as diretrizes do NASF.

A dificuldade de pactuar e de executar as ações preconizadas, como o apoio matricial, tem origem nas principais reflexões sobre os processos de implantação. Campos e Dominitti (2007) apontam que os principais obstáculos para efetivação do apoio matricial estão em diversos aspectos da maneira como tradicionalmente se organizam as instituições de saúde no Brasil. Dentre os obstáculos enunciados pelos autores pode-se destacar dois que têm relação direta com o cenário apresentado nos NASFs estudados: os estruturais e os decorrentes do excesso de demanda e carência de recursos.

Os obstáculos estruturais referem-se à organização departamental que muitas organizações de saúde adotam, e os NASFs de ambos os municípios parecem reforçar esse obstáculo pela prática dos ambulatórios "não institucionalizado" e "comunitário", com uso de salas separadas para profissionais na realização de atendimentos individuais (com um indivíduo, por um profissional) no Centro de Especialidades (NASF do município A), e nas salas disponíveis nas USFs, à mercê do cronograma da ESF (NASF do município B). Curioso que Campos e Dominitti (2007) propõem como solução para esse obstáculo ao apoio matricial o próprio apoio acrescido do Projeto Terapêutico Singular (PTS), ambos ausentes nos dois NASFs, o que denota a importância que a própria estrutura de funcionamento tem na implementação do apoio.

O segundo obstáculo é decorrente do excesso de demanda e carência de recursos e encontra uma forte predominância, sobretudo quando se realizam os processos de implantação e implementação dos NASFs referidos. Campos e Dominitti (2007) defendem que é preciso repensar as práticas de gestão e atenção frente à parcialidade da implantação e implementação do SUS. Dado o seu caráter dual, mudanças estruturais são de difícil aplicação e aceitação, mas nem por isso podem ser consideradas menos importantes. A questão que tal autor defende se refere à promoção de práticas de gestão e atenção de forma mais racional em relação ao acesso e aos recursos que são empreendidos no SUS.

Tal situação pode ter em suas origens, também, algumas distorções práticas na atuação. Segundo documento do Conselho Federal de Psicologia (2009), alguns estudiosos e trabalhadores da saúde inseridos em NASF entram em consenso ao colocar que grande parte dos problemas com o excesso de demanda se deve ao fato de muitos profissionais, principalmente os psicólogos, fazerem de toda demanda de saúde uma demanda clínica. Esse "clinicismo" não somente gera grandes entraves, como também se distancia das perspectivas preconizadas para o serviço da clínica ampliada, o que traz obstáculos para a execução de outras ações como os PTSs e os PSTs. Nos NASFs de ambos os municípios estudados, a manutenção de um atendimento clínico desvinculado das demais atividades do serviço torna-se preocupante não só pela dualidade da prática, mas pelo aporte tradicional (baseado no modelo médico, individualista, privatista e curativista) ao qual a atuação das psicólogas estudadas se aproxima.

Diante da impossibilidade de condições favoráveis a uma atuação de acordo com suas orientações profissionais (a terapia humanista-existencial da psicóloga do NASF do município A e a terapia cognitivo-comportamental das duas psicólogas do NASF do município B), as psicólogas manifestaram durante todas as entrevistas uma distorção peculiar na concepção do conceito de atendimento, que interfere diretamente na prática cotidiana e revela o ideário individualista e segmentado dessas. $\mathrm{O}$ atendimento é relatado por diversas vezes como atendimento individual, que deveria ser atendimento compartilhado, ocorrendo de forma multiprofissional com a ESF. Os documentos que balizam o NASF preveem que o atendimento deve ser sempre compartilhado, na medida em que somente dessa forma uma perspectiva de atendimento ao usuário pode vislumbrar coerência com a perspectiva de apoio matricial às ESFs maior do que com o paralelismo de atuações "especializadas" ou centradas no atendimento por um profissional. 
Essa distorção se reflete na dificuldade também apresentada em atuar de forma distinta de suas formações, que as prepararam para uma abordagem tradicionalmente relacionada às atividades autônomas e liberais, como a dinâmica de um consultório particular de Psicologia, fenômeno recorrente na história dos cursos de Psicologia brasileiros (Coimbra, 2004; Cruces, 2006; Bastos \& Gondin, 2010). O caráter privado e o status elitista de tal campo o direcionam notadamente a uma parcela mais abastada da sociedade, diametralmente oposta ao contexto social pungente da demanda característica da atenção básica em saúde: a população pobre dos municípios, haja vista que a ESF, ainda que levante a bandeira da "universalidade", acaba por se realizar como "focalizada" neste público (Sisson, 2007).

O descompasso da prática com o contexto em que ela se insere não é somente um descompasso de campos de atuação, mas também um descompasso temporal. O perfil da prática das psicólogas estudadas remete mais a princípios e discussões que norteavam os estudos de especialista da área clínica à época de implantação da Estratégia de Saúde da Família, ainda como programa nos anos 1990 (Lo Bianco, Bastos, Nunes, \& Silva, 1994), do que às discussões mais atuais, como, por exemplo, a clínica ampliada.

Campos (1997) define que essa "clínica oficial", mesmo com todas as suas limitações advindas dos reducionismos da medicina, pode ser ainda mais inócua configurando o que o autor denomina de "clínica degradada". Por influência de fatores externos, como orientações políticas ou econômicas de instituições, o clínico passa a atender de forma padronizada, sem atentar para diferenças de gravidades dos casos ou para as necessidades do usuário. Essa é a clínica da queixa-conduta, da eficiência, da produção de procedimentos e centrada no sintoma (Onocko, 2001).

Essa "clínica oficial" também apresenta sérias limitações no que diz respeito ao seu alcance, devido a um enfoque especializado na doença ou no "órgão doente", e negligente à multiplicidade dos aspectos do processo saúdedoença (Campos, 1997). Uma das principais consequências desse reducionismo é a legitimação de uma prática clínica cada vez mais especializada, interdependente e fragmentada, cujos processos de trabalho tornam-se de difícil integração, mesmo com projetos terapêuticos completos.

Essa característica também afasta o fazer clínico das perspectivas de prevenção, promoção e até mesmo reabilitação tão caras à saúde brasileira, principalmente na atenção básica (Ministério da Saúde, 2006). Não se quer dizer, aqui, que o atendimento à população deva ser suprimido, mas deve, sim, e em todas as circunstâncias que existir, ser compartilhado; não deve, também, ser a única ferramenta de intervenção, visto a maior potencialidade e resolutividade de outras ferramentas que contextualizam o território e se embasam numa concepção de realidade do usuário como multideterminada (como o Projeto Terapêutico Singular e o Projeto de Saúde no Território).

Longe de estabelecer as condições de efetivação da preconizada clínica ampliada, as psicólogas de ambos os
NASFs coadunam com formas incipientes de uma conduta clínica, seja "tradicional" ou "degradada". O desenvolvimento de uma atuação incerta se desenrola numa "terra de ninguém", onde nem conseguem estabelecer as condições básicas para o aporte típico de consultório (setting terapêutico, sigilo e silêncio, entre outras), e tampouco atentam para uma ampliação da clínica. A atuação psicológica acaba por se dar em momentos de escuta, orientação e tentativas de "evolução de casos".

Uma das funções do apoio matricial é propor um rearranjo no modelo organizacional reinante na atenção básica, extremamente fragmentado e verticalizado entre os profissionais da USF. Mas não deve ser desconsiderada a importância da própria equipe NASF aderir uma perspectiva horizontal de funcionamento: na medida em que um dos "braços" do contato com a Estratégia de Saúde da Família é o atendimento ambulatorial dissociado da própria equipe de referência, os profissionais do NASF se tornam apenas uma "referência especializada". Por outro lado, ao mesmo tempo existem ações coletivas (ou a intenção delas) em conjunto com a ESF. Tal dualidade torna-se não apenas contraditória, mas cinde a equipe: de um lado, os "especialistas" e, de outro, os "apoiadores".

A vertente "apoiadora" dos NASFs do município B é singular na medida em que, mesmo sem o apoio matricial efetivo, o terreno necessário para sua efetivação está sedimentado. A busca por uma atuação e integração na rede de práticas diferenciadas do atendimento ambulatorial exclusivo do início das práticas dos NASFs encontrou seu prumo na realização e acompanhamento de diversas atividades coletivas como: grupos, tanto os criados pelo NASF quanto os inseridos nos já existentes; recorrente capacitação das ENASFs e destas para com parceiros; e projetos de inserção da atenção básica em outras instituições do município, como o Programa Saúde na Escola (PSE) e o Programa Educacional de Resistência às Drogas e à Violência (PROERD).

A atuação do "especialista", por sua vez, se dá de forma individualizada, coerente com a fragmentação típica dos "especialismos": mesmo o contexto se mostrando complexo e multideterminado, por fim acabam "tratando" o usuário desvinculado da sua família e da comunidade em que se insere. Assim como no município A, a criação de uma demanda inicial de atendimentos reverbera na prática, mesmo após contínuas atividades de ressignificação do NASF do município B. No NASF do município A é mais fácil perceber apenas o lado do "especialista", visto que não houve mudanças tão significativas na forma de realizar os atendimentos individuais mesmo no momento de transição de um "ambulatório não-institucionalizado" para atuar como NASF.

Uma peculiaridade do NASF do município A, durante o período de entrevistas, foi um remanejamento da coordenação e um subsequente início de reflexão sobre a prática realizada até então. A psicóloga passou a assumir a coordenação e o antigo coordenador passou a trabalhar como especialista ambulatorial, não mais vinculado ao 
NASF. Esse era o momento de outra transição, mais próxima a questionamentos capazes de impulsionar uma prática matricial e ampliada. Assim, defende-se que a grande mudança a empreender é a saída do lugar de "especialistas" para o de "apoiadores", reconhecer onde há potencialidade para ampliar e pactuar as ações com a ESF.

Mesmo reconhecendo que as ações que emulam o apoio matricial aconteçam de modo informal no NASF do município A, as noções sobre esta e outras possibilidades de trabalho do NASF são ainda incipientes para a psicóloga. A necessidade de cumprir com as atividades e princípios do caderno 27 (Ministério da Saúde, 2009a) fica estagnada por uma conduta "doutrinária", que adota as diretrizes como "manual" a ser seguido e pontua ações e procedimentos, realizados ou não. Tal direcionamento pode ter origem em um posicionamento da gestão, mas, independentemente disso, essa forma de encarar os documentos oficiais, acrítica e irreflexiva, corrobora com questões discutidas em estudos sobre profissionais de saúde, incluindo o psicólogo (a exemplo de Scarcelli e Junqueira, 2011).

Preocupações com a origem histórica dos conhecimentos produzidos e com o confronto de interesses que marca a criação e implementação de políticas, projetos e práticas têm papel fundamental no contexto atual do trabalho do psicólogo na saúde pública: há necessidade de que seja uma espaço democrático, propício a compartilhamento de saberes diversos e flexibilização de estruturas estanques dos conhecimentos e técnicas "tradicionais", formais. À concepção de um profissional "conformado" e "adaptável", que não se coloca ou se posiciona frente a esses questionamentos, se contrapõe o caráter ativo de participação do mesmo no processo, precipitando o desvelar de modos de produção de práticas e ideologias que subjazem no cotidiano das instituições e políticas de saúde.

Essa tensão imanente, o deparar-se com diretrizes novas para a profissão e como utilizá-las, assim como o dilema profissional "especialista" versus "apoiador", nos coloca questionamentos não apenas sobre o viés da atuação psicológica e sua formação, mas também sobre as expectativas da população e de outros profissionais sobre o papel do psicólogo. Podem-se fazer alguns apontamentos sobre esse aspecto remetendo a recorrente expectativa de atuação para o psicólogo pelo que comumente ele é reconhecido: o fazer clínico.

Não somente a população espera do psicólogo uma terapêutica, uma escuta diferenciada de outros profissionais, mas também as gestões em saúde e coordenadores se aglutinam a essa expectativa acerca do trabalho do psicólogo e, assim, direcionam a escolha pela admissão de profissionais que satisfaçam esse perfil desejado de atuação. A clínica, de forma geral, pode ser o modus operandi dos serviços de atenção básica à saúde, mas a clínica psicológica certamente é a mais questionada quanto à inadequação aos princípios de integralidade e promoção da saúde.

É plausível afirmar que mesmo que a perspectiva de inserção dos profissionais do NASF como apoiadores da ESF ocorresse, tanto nas ações coletivas quanto nos atendimentos ambulatoriais realizados pela própria Equipe de Saúde da Família, ainda haveria complicações nesse arranjo operativo, principalmente pela reminiscência de aspectos burocráticos das antigas Unidades Básicas de Saúde (UBS) no NASF. Tal inserção configuraria uma atuação diferente da mera reprodução de práticas ambulatoriais pela ENASF de ambos os municípios, uma emulação dos processos de trabalho das ESF - "ambulatório não institucionalizado" ou "ambulatório comunitário" - mas não questionariam, de fato, a necessidade de cumprimento de metas e produtividade da atenção básica impostas pelo Ministério da Saúde - metas relacionadas à prática que privilegia $o$ atendimento ambulatorial em relação a outras formas, por vezes mais contextualizadas, mas sem representatividade nas fichas avaliativas do serviço.

É notório como a influência das contrapartidas das agências internacionais de financiamento, como o Banco Mundial e o Fundo Monetário Internacional, tem repercussões que, apesar de aparentarem entraves organizativos das instituições de saúde, remontam a um cumprimento de contrato entre o governo brasileiro e as agências financiadoras da saúde pública brasileira (Mattos, 2001; BresserPereira, 2002). O aspecto do cumprimento de metas de indicadores relacionado à quantidade de procedimentos realizados ilustra essas repercussões. Assim como as ESFs, as equipes do NASF também necessitam preencher relatórios de produtividade nos quais há contrapartidas por realização de procedimentos, de forma fragmentada, que não condizem com a própria política regulamentadora do NASF, e tampouco com as atividades imprecisas realizadas por essas equipes.

Essa preocupação com o cumprimento das metas não é apenas incoerente com as fundamentações das políticas reestruturantes da atenção básica, como revela a característica marcante da condução governamental das políticas de saúde no Brasil, reforçada em várias frentes por partidários dos ajustes neoliberais pactuados com as agências supracitadas. Tal condução é pautada por um sucessivo sucateamento do sistema público de saúde, enquanto em paralelo há um suporte diferenciado para a iniciativa médica privada (Menicucci, 2006), ainda que haja luta contra as perspectivas reformistas das políticas de saúde, visando promover maior integralidade e equidade das práticas básicas em saúde (Cohn, 1989; 1994).

Pode-se inferir, por fim, que o ponto em comum que influi de forma predominante na reiteração de certas práticas é o papel da gestão, que acaba por contribuir para a manutenção de um padrão: apesar de haver experiências buscando inovar no campo, o atendimento clínico continua recorrente na atuação do psicólogo na saúde pública. Tal padrão de atuação encontra subsídios para acontecer não só no ideário compactuado por muitos em relação às expectativas sobre a atuação "psicologizante" da Psicologia, mas também na própria estruturação do serviço.

Em ambos os municípios, o processo de implantação se configurou com distorções que, se não pareciam claramente opostas com o que era preconizado pela portaria 
$\mathrm{n}^{\mathrm{o}} 154 / \mathrm{GM}$, emergiam com mais força com a chegada de outros documentos, como as diretrizes do NASF. Não se está aqui conferindo centralidade impertinente a tal documento, visto que reúne diversas referências sobre perspectivas que intentam distanciar-se de práticas tradicionais em saúde. Entende-se também que a compreensão dessas diretrizes como receituário, por parte dos profissionais, não ocorre de forma homogênea, mas ao corroborar com uma tradição unidirecional da implementação de políticas pelo Ministério da Saúde, instalando-se uma contradição fundamental: a de cobrar dos profissionais práticas promotoras de horizontalidade nas relações entre profissionais e suas práticas, horizontalidade na construção de saberes interdisciplinares sem preconizar a mesma horizontalidade nos processos de decisão sobre as políticas implementadas.

As contradições remetem também à grande dissociação entre as perspectivas da reforma sanitária e da reforma psiquiátrica, que estiveram imbuídas de um interesse comum com mais força nos movimentos pró-democracia à época da ditadura civil-militar no país que no momento atual, em que por vezes esses dois movimentos defendem pontos de vista conflitantes. Sobre as ações preconizadas pelos documentos oficiais, percebem-se também similaridades e algumas diferenças. Nenhuma das quatro ferramentas de trabalho principal do NASF é realizada conforme o preconizado. A ferramenta central, o apoio matricial, é relatada por ambas as equipes como a de implementação mais difícil. O que se está intentando relacionar é que tal nuança da atuação efetiva das psicólogas tem correlações mais próximas com a reprodução de um saber hegemônico, seja de forma compactuada ou despercebida, do que com tentativas de inovação.

\section{Considerações finais}

Este estudo pretendeu apontar a necessária discussão sobre as repercussões que os saberes e práticas psicológicos acarretam para a população que atravessam. Considera-se de suma importância, tanto do ponto de vista ético quanto acadêmico, que sejam questionadas as práticas que se sustentam sobre os fundamentos de um discurso hegemônico, discurso que esconde um mote perverso. Concorda-se com a concepção de Pastorini (2007) segundo a qual tal posicionamento implica romper com a chamada história oficial compactuada por tantos, e passa a considerar o "consenso manipulado, construído artificialmente na sociedade capitalista" (p. 95). Essa história oficial contada por tantos dilui diferenças sociais e culturais e banaliza as desigualdades sociais com argumentos generalistas.

Assume-se que o que se está chamando de "clínica tradicional", termo recorrentemente usado no decorrer de todo o texto, refere-se à clínica que compactua com essa história. Em nenhum momento aqui pretende-se afirmar que as perspectivas que se utilizem de um viés clínico sejam necessariamente descontextualizadas da realidade - diversas são as correntes de pensamento que almejam encontrar alternativas à hegemonia, mesmo que utilizandose desse viés, e não se está desmerecendo tais esforços. De outro modo, espera-se que o presente estudo contribua para que o debate político não esteja dissociado das práticas da Psicologia, principalmente quando esta se insere no campo das políticas sociais.

A partir dessa perspectiva, os limites colocados pelo modo de produção capitalista apontam justamente para um realismo frente aos sonhos do psicólogo como profissional capaz de transformar a sociedade. Tais limites não excluem a possibilidade de que diferentes práticas psicológicas possam apresentar novas direções, mais comprometidas ou mais críticas, ainda que essas não superem ou mesmo tensionem esse limite.

Pensar e discutir como o modo de produção vigente produz o "sujeito psicólogo", e como este reproduz a ideologia oriunda das classes dominantes nas relações com seus congêneres e na sua prática, torna-se cada vez mais necessário e pungente no momento histórico atual. As perguntas "qual posição tomar?" e "qual direção seguir?" tornam-se cada vez mais "qual posição criar?" e "qual caminho construir?". É preciso "andar veredas".

\title{
Between specialism and support: psychologists in Support Center for Family Health
}

\begin{abstract}
The institution of Núcleo de Apoio a Saúde da Família (NASF) at 2008 structured multiprofessional and interdisciplinary teams, in which psychologists are considered main professional. Models related to psychological actions are not defined, raising questions about implications about a work that is health caring as much as managing service. This study aims to clarify the connection between NASF's deployment process and the effective practice of psychologist inserted at the service, at two cities of Rio Grande do Norte (RN). It was used analysis of official documents and different semi-structured interviews to psychologists (3) and coordinators (2). Through a comparison analysis may be infered that the psychological practice reveals a traditional approach and reproduces practices from different institutions. Also, the differences of services deployment process set a way to revert that logic.
\end{abstract}

Keywords: Support Center for Family Health, psychologist practice, health policy, family health. 


\section{Entre le spécialisme et le suport: Psychologues dans le “Núcleo de Apoio à Saúde da Família (Noyaux de Suport à la Santé de la Famille)}

Résumé: L'insertion du psychologue en équipes multiprofessionnelles et interdisciplinaires pour le support aux équipes de santé de la famille, à partir de la création des NASFs (Núcleos de Apoio a Saúde da Família - Noyaux de Support à la Santé de la Famille) en 2008, a été priorisé, même sans un profil nette pour son action. Cela a provoqué le questionement des implications d'un travail destiné à l'attention et à la gestion pour la Psychologie. L'intention a été d'analyser le processus d'implantation du NASF et la pratique des psychologues dans deux villes de l'état du Rio Grande do Norte. On a utilisé l'analyse des documents officiels et des dialogues d'entretien semiestructurés distingués, pour des psychologues ( 1 de la ville $A$ et 2 de la ville B) et des coordinateurs ( 2 , un de chaque ville). On peut comprendre que l'actuation a eposé des mises au point plutôt traditionnels et une reproduction d'activités d'autres institutions. On peut conclure que les différences sur les processus d'implantation des services créent eux mêmes les instrument pour la reversion de cette logique.

Mots-clés: Noyeau de Support à la Santé de la Famille, actuation du psychologue, politiques de santé, santé de la famille.

\section{Entre el soporte y especialización: psicólogos en Centros de Apoyo a Salud de la Familia}

Resumen: La inclusión de psicólogos en equipos multidisciplinarios e interdisciplinarios para apoyar a los equipos de salud de la familia, desde la creación de Núcleos de Apoio a Saúde da Família en 2008, se dio prioridad, aunque sin un perfil claro para su actuación. Esto llevó al cuestionamiento de las implicaciones de un trabajo dirigido a la atención y gestión para la Psicología. Este estudio tuvo como objetivo analizar el proceso de implementación del NASF y la práctica de los psicólogos en dos municipios del estado de Rio Grande do Norte. Se utilizó el análisis de documentos oficiales y guiones diferentes de entrevistas semi-estructuradas a los psicólogos (uno de la ciudad A y dos de la ciudad B) y coordinadores ( 2 , uno de cada ciudad). Resultó que la actuación psicológica revela enfoques tradicionales y una reproducción de actividades de otros contextos y se conclui que las diferencias en los procesos de implementación de servicio crean los instrumentos para revertir esta lógica.

Palabras-clave: Centros de Apoyo a Salud de la Familia, actuación del psicólogo, políticas de salud, salud de la familia.

\section{Referências}

Bastos, A. V. B., \& Gondim, S. M. G. (2010). O trabalho do psicólogo no Brasil. Porto Alegre, RS: Artmed.

Bresser-Pereira, L. C. (2002). Financiamento para o subdesenvolvimento: o Brasil e o segundo Consenso de Washington. In A. C. Castro (Org.), Desenvolvimento em debate: painéis do desenvolvimento brasileiro I (vol. 2, pp. 359-398). Rio de Janeiro, RJ: MAUAD/BNDES.

Campos, G. W. S. (1997). Uma clínica do sujeito: por uma clínica reformulada e ampliada [Mimeo]. Campinas, SP.

Campos, G. W. S. (1999). Equipes de referência e apoio especializado matricial: uma proposta de reorganização do trabalho em saúde. Ciência Saúde Coletiva, 4, 393-404.

Campos, G. W. S. (2006). Efeito paidéia e o campo da saúde: reflexões sobre a relação entre o sujeito e o mundo da vida. Trabalho, Educação e Saúde, 4, 19-31.

Campos, G. W. S., \& Dominitti, A. C. (2007). Apoio matricial e equipe de referência: uma metodologia para gestão do trabalho interdisciplinar em saúde. Cadernos de Saúde Pública, 23(2), 399-407.

Cohn, A. (1989). Caminhos da Reforma Sanitária. Lua Nova, 89, 123-140.

Cohn, A. (1994). Mudanças econômicas e políticas de saúde no Brasil. In A. C. Laurell (Org.), Estado e politicas sociais no neoliberalismo (pp. 225-244). São Paulo, SP: Cortez.
Cohn, A. (2005). O SUS e o direito à saúde: universalização e focalização nas políticas de saúde. In N. T. Lima, S. Gerchman, \& F. C. Edler, (Orgs.), Saúde e democracia: história e perspectivas do SUS (pp. 385-405). Rio de Janeiro: Fiocruz.

Coimbra, M. B. C. (2004). Práticas “psi” no país do "milagre": algumas de suas produções. Mnemosine, 1, 44-52.

Conselho Federal de Psicologia. (2009). A prática da psicologia e o núcleo de apoio à saúde da família. Brasília: Autor.

Cruces, A. (2006). Egressos de cursos de Psicologia: preferências, especializações, oportunidades de trabalho e atuação na área educacional (Tese de doutorado). Universidade de São Paulo, São Paulo. Disponível em: http://www.teses.usp.br/teses/disponiveis/47/47131/tde08082006-151346/pt-br.php

Cunha, G. T. (2005). A construção da clínica ampliada na atenção básica. São Paulo, SP: Hucitec.

Heimann, L. S., \& Mendonça, M. H. (2005). A trajetória da atenção básica em saúde e do Programa de Saúde da Família no SUS: uma busca de identidade. In N. T. Lima, S. Gerchman, \& F. C. Edler,(Orgs.), Saúde e democracia: história e perspectivas do SUS (pp. 481-502). Rio de Janeiro, RJ: Fiocruz.

LoBianco, A. C., Bastos, A. V. B., Nunes, M. L. T., \& Silva, R. C. (1994). Concepções e atividades emergentes 
na Psicologia Clínica: implicações para a formação. In Conselho Federal de Psicologia (Org.), Psicólogo brasileiro: práticas emergentes e desafios para a profissão (pp. 7-79). São Paulo, SP: Casa do Psicólogo.

Mattos, R. A. (2001). As agências internacionais e as políticas de saúde nos anos 90: um panorama geral da oferta de idéias. Ciência \& Saúde Coletiva, 6(2), 377-389.

Menicucci, T. M. G. (2006). Política de saúde no Brasil: entraves para universalização e igualdade da assistência no contexto de um sistema dual. Serviço Social $e$ Sociedade, 26(87), 28-75.

Ministério da Saúde. (2006). Política Nacional de Atenção Básica [Série Pactos pela Saúde, vol. 4]. Brasília, DF: Autor.

Ministério da Saúde. (2008a, 04 de março). Portaria 154 de 24 de janeiro de 2008. Cria os Núcleos de Apoio à Saúde da Família - NASF. Diário Oficial da União, 43, 38-42.

Ministério da Saúde. (2008b, 23 de julho). Portaria $N^{\circ} 409$, de 23 de julho. Institui a FCES - Ficha Complementar de Cadastro das Equipes de Núcleo de Apoio à Saúde da Família - NASF, no Sistema de Cadastro Nacional de Estabelecimento de Saúde - SCNES. Diário Oficial da União, 23 de julho de 2008.

Ministério da Saúde. (2009a). Caderno 27 - Diretrizes do $N A S F$. Brasília, DF: Autor.

Ministério da saúde. (2009b). Clínica ampliada e compartilhada. Brasília, DF: Autor.
Netto, J. P. (2001). Crise do Socialismo e ofensiva neoliberal. São Paulo: Cortez.

Netto, J. P. (2011). Introdução ao estudo do método de Marx. São Paulo, SP: Expressão Popular.

Onocko, R. (2001). Clínica: a palavra negada - sobre as práticas clínicas nos serviços substitutivos de Saúde Mental. Saúde em Debate, 25(58), 98-111.

Pastorini, A. (2007). A categoria "questão social" em debate. São Paulo, SP: Cortês.

Sales, I. C., \& Pagani, R. (2004). A preceptoria de território na estratégia de saúde da família em Sobral/CE. SANARE: Revista Sobralense de Políticas Públicas, 1(1), 41-46.

Scarcelli, I. R., \& Junqueira, V. (2011). O SUS como desafio para a formação em Psicologia. Psicologia: Ciência e Profissão, 31(2), 340-357.

Sisson, M. C. (2007). Considerações sobre o Programa de Saúde da Família e a promoção de maior eqüidade na política de saúde. Saúde e Sociedade, 16(3), 85-91.

Viana, A. L. D., \& Dal Poz, M. R. (2005). A reforma sanitária do sistema de saúde no Brasil e o Programa de Saúde da Família. Physis, 8, 225-264.
Recebido : 10/07/2014

Revisado: $15 / 01 / 2015$

Aceito: $21 / 04 / 2015$ 